\title{
Estudo comparativo de previsões de recalque em fundações profundas e seus efeitos
}

\section{na interação solo-estrutura}

\author{
Comparative study of settlement predictions in mat foundations and their effects on soil-structure
}

interaction

Estudio comparativo de predicciones de assentamentos en cimentaciones profundas y sus efectos en

la interacción suelo-estructura

Recebido: 13/07/2021 | Revisado: 19/07/2021 | Aceito: 22/07/2021 | Publicado: 29/07/2021

\author{
Eurico de Lira Araujo Junior \\ ORCID: https://orcid.org/0000-0003-4006-7579 \\ Universidade Federal de Pernambuco, Brasil \\ E-mail: jjloren@hotmail.com \\ Silvio Romero de Melo Ferreira \\ ORCID: https://orcid.org/0000-0002-5760-1494 \\ Universidade Federal de Pernambuco, Brasil \\ E-mail: silvio.mferreira@ufpe.br \\ Alexandre Duarte Gusmão \\ ORCID: https://orcid.org/0000-0002-7817-6124 \\ Universidade de Pernambuco, Brasil \\ E-mail: gusmao.alex@upe.br
}

\begin{abstract}
Resumo
Mecanismos como Interação Solo-Estrutura (ISE) e Efeito Incremental Construtivo (EIC) são cada vez mais usados em detrimento de modelos que consideram os pilares como apoios fixos. Ocorre que para uma correta análise da ISE e do EIC, é fundamental uma predição satisfatória dos recalques. Este trabalho objetiva comparar os efeitos de diversos métodos de previsão de recalque na ISE, e consequentemente, comparar seus efeitos na distribuição de esforços axiais e de momentos fletores em um edifício de concreto armado cuja fundação é constituída por estacas hélice contínua. Ao mesmo tempo, o trabalho visa a comparar os esforços obtidos com o emprego de EIC em modelo de pilares com apoios fixos, com o modelo que emprega o EIC associado a deslocamentos prescritos dos pilares. As previsões dos recalques foram realizadas através de métodos consagrados na literatura e por norma brasileira. Os deslocamentos prescritos foram obtidos em função do monitoramento de recalques do edifício. Os resultados mostraram que as predições de recalques podem variar significativamente de uma para outra. Além disso percebeu-se que alguns pilares apresentaram comportamento contrário ao esperado quando empregada a interação solo- estrutura, pois quando considerado o referido mecanismo, a expectativa é que pilares centrais diminuam sua carga ao passo que os pilares periféricos aumentem sua carga. A utilização do modelo clássico, ou seja, pilares considerados como sendo fixos, assim como a consideração de modelos que contemplam ISE, podem resultar em esforços de magnitudes bem diferentes, conduzindo a incertezas que se refletem na segurança das estruturas e fundações.
\end{abstract}

Palavras-chave: Interação solo-estrutura; Estacas hélice contínua; Previsão de recalques; Deslocamentos prescritos.

\begin{abstract}
Mechanisms such as soil-structure interaction (SSI) and Construction Sequence (CS) are increasingly used to the detriment of models that consider columns as fixed node supports. It occurs that for a correct analysis of SSI and CS is fundamental a satisfactory prediction of settlements. This work aims to compare the effects of several settlement prediction methods on the SSI, and consequently, compare their effects on the distribution of axial forces and bending moments in a reinforced concrete building whose foundation is constituted by continuous flight auger piles. At the same time, the work aims to compare the efforts obtained with the use of CS in a fixed columns support model, with the model that employs the CS associated with prescribed displacements of the columns. Settlements predictions were carried out using methods established in the literature and according to the Brazilian standard. Prescribed displacements were obtained as a function of the building settlement monitoring. The results showed that settlement predictions can vary significantly from one to another. Furthermore, it was noticed that some columns presented behavior contrary to the expected when the soil-structure interaction is used, because when considering the referred mechanism, the expectation is that central columns reduce their load while the peripheral columns increase theirs. The use of the classic model, that is, Columns considered as fixed nodes, as well as the consideration of models that include SSI, can result in efforts of very different magnitudes, leading to uncertainties that are reflected in the safety of structures and foundations.
\end{abstract}

Keywords: Soil-structure interaction; Continuous flight auger piles; Settlement prediction; Prescribed displacements. 


\begin{abstract}
Resumen
Mecanismos como Interacción Suelo-Estructura (ISE) y Efecto Incremental Constructivo (EIC) se utilizan cada vez más en detrimento de modelos que consideran las columnas como soportes fijos. Ocurre que para un correcto análisis del ISE y EIC, es fundamental una predicción satisfactoria de asentamientos. Este trabajo pretende comparar los efectos de varios métodos de predicción de asentamientos sobre el ISE y, en consecuencia, comparar sus efectos sobre la distribución de fuerzas axiales y momentos flectores en una edificación de hormigón armado cuya cimentación está constituida por pilotes de hélice continua. Al mismo tiempo, el trabajo pretende comparar los esfuerzos obtenidos con el uso de EIC en un modelo de columna con apoyos fijos, con el modelo que emplea la EIC asociada a los desplazamientos prescritos de las columnas. Las predicciones de asentamientos se realizaron utilizando métodos establecidos en la literatura y de acuerdo con la norma brasileña. Los desplazamientos prescritos se obtuvieron en función del seguimiento de asentamientos en el edificio. Los resultados mostraron que las predicciones de asentamientos pueden variar significativamente de unas a otras. Además, se notó que algunas columnas se comportaron de manera contraria a lo esperado cuando se emprega la interacción suelo-estructura, pues al considerar el mecanismo antes mencionado, la expectativa es que las columnas centrales reduzcan su carga mientras que las columnas periféricas aumentan su carga. La utilización del modelo clásico, es decir, pilares considerados fijos, así como la consideración de modelos que incluyan ISE, puede resultar en esfuerzos de muy diversa magnitud, dando lugar a incertidumbres que se reflejan en la seguridad de estructuras y cimentaciones.
\end{abstract}

Palabras clave: Interacción suelo-estructura; Pilotes de hélice continua; Predicción de asentamiento; Desplazamientos prescritos.

\title{
1. Introdução
}

A prática de projetos geotécnicos e estruturais indica que a grande maioria das obras ainda é concebida considerando os pilares como apoios fixos, e com essa condição, são dimensionados os elementos de fundações e das estruturas. De acordo com Farias (2018), o emprego de uma metodologia que permita acoplar a superestrutura, a infraestrutura e o maciço do solo em um único modelo, pode produzir resultados mais representativos da estrutural real. No entanto, o referido modelo exige um elevado poder de processamento computacional, uma vez que deverá considerar mecanismos tais como Interação Solo Estrutura (ISE) e Efeito Incremental Construtivo (EIC), assim como o comportamento do solo ante a esses mecanismos. Por essa razão, quando se empregam modelos mais refinados, normalmente o comportamento estrutural não é tratado em conjunto com o comportamento do solo.

Para uma correta análise de ISE é preciso entender o comportamento do solo, sobretudo na previsão de recalques. No caso de fundações profundas, essa análise se torna ainda mais complexa, uma vez que as estacas interagem entre si em um mecanismo conhecido como efeito de grupo. Diversos autores se dedicaram à previsão desse efeito. Skempton (1953) e Meyerhof (1959) empregaram métodos empíricos baseados na geometria da fundação. Aoki e Lopes (1975) e Poulos e Davis (1980) empregaram métodos elásticos em que se consideravam as propriedades das estacas e do solo em que aquelas estão inseridas. Hamderi (2018) procurou traduzir numericamente o comportamento 3D de um grupo de estacas, apresentando uma fórmula baseada em características geométricas do bloco e de propriedades da estaca e do solo. Autores como Sales et al. (2017) mostraram como o processo de execução da estaca interfere no efeito de grupo, ao passo que Gusmão, Silva e Sales (2020) provaram a importância de considerar a interação entre os diferentes elementos de uma fundação na previsão de recalques.

A previsão do comportamento do solo, em conjunto com os elementos de fundação, irá impactar no efeito de grupo. A referida previsão não é tarefa fácil e está associada ao modelo adotado. Homaei, Shakib e Soltani (2017) e Qaftan et al. (2020) modelaram o solo utilizando elementos finitos para avaliar o comportamento de prédios de diversos pavimentos. AsadiGhoozhdi e Attarnejad (2020) usaram o método de Winkler em vigas de comportamento não linear. Dhadse, Ramtekkar e Govardhan (2020) empregaram modelos em que consideravam o comportamento linear e não-linear do solo, concluindo que os modelos baseados no método de elementos finitos eram mais adequados para contemplar a ISE. No entanto, Gowthaman, Nasvi e Krishnya (2017) demonstraram que mesmo modelos mais bem elaborados do solo, como no caso da consideração da não-linearidade, podem se revelar inadequados. 
Iwamoto (2000) afirma que dentre as vantagens em considerar a ISE, está a possibilidade de estimar os efeitos da redistribuição de esforços nos elementos estruturais, assim como a forma e a intensidade dos recalques diferenciais, tornando os projetos mais eficientes e confiáveis. Uma das formas de se realizar a ISE é através do processo interativo. Gusmão, Silva e Sales (2020) explicam que o referido processo começa com a obtenção das cargas nos pilares considerando-os apoios fixos. Utilizando essas cargas, os recalques são obtidos para cada pilar. Obtém-se então um coeficiente de mola inicial, que é a relação entre a carga e o recalque encontrados. A estrutura é então reiteradamente calculada, encontrando-se novas cargas e recalques nos pilares até que haja uma convergência em uma das variáveis. Aoki (1997), Bahia (2015) e Silva (2018) utilizaram o processo interativo em suas pesquisas. Os autores relataram importantes redistribuições de esforços quando da utilização do referido processo.

Gusmão (1990), Danziger, Costa e Danziger (2005) e Savaris, Hallak e Maia (2011) verificaram que solidariedade existente entre os elementos da estrutura confere a mesma considerável rigidez, restringindo o movimento relativo entre os apoios e fazendo com que os recalques diferenciais sejam menores que os estimados convencionalmente. Ocorre que o EIC desempenha um importante papel na ISE, uma vez que à medida que os pavimentos das estruturas são construídos, sua rigidez sofre um aumento (Gusmão Filho, 1998). Analisando o EIC, Yip, Au e Smith (2011) verificaram que o encurtamento axial diferencial de pilares é reduzido pela ação do tempo, afetando tensões e momentos nas estruturas. Modelando 16 estruturas espaciais para cada estágio de carga na construção de 13 andares, Menon e Nogueira (2015) observaram migrações de cargas entre pilares da ordem de 60\%. Outros autores como Kripka (1990), Prado (1999), Leite (2015) e Panigrahi et al. (2019), também atestaram a importância de se considerar o EIC.

Partindo da modelagem de um edifício composto por múltiplos pavimentos e utilizando instrumentos como a ISE e EIC, o objetivo deste estudo é comparar diferentes métodos de obtenção de recalques, em que se considera o efeito de grupo de estacas, assim como deslocamentos prescritos, em termos de distribuições de ações verticais estáticas nos apoios dos pilares e de momentos em pórticos espaciais.

\section{Obtenção de Recalques com a Consideração de Efeito de Grupo}

O método de Meyerhof (1959) consiste em uma formulação que leva em conta o espaçamento, o diâmetro e a geometria das estacas conforme apresentado na Equação 1.

$\xi=\zeta\left(\frac{5-\frac{\zeta}{3}}{\left(1+\frac{1}{n_{r}}\right)^{2}}\right)$

em que: $\xi$ - relação entre o recalque de um grupo de estacas e o recalque de uma única estaca submetida a sua parcela de carga no grupo; $\zeta$ - razão entre o espaçamento das estacas e o diâmetro das estacas; $\mathrm{n}_{\mathrm{r}}$ - número de linhas de estacas num bloco quadrado.

Aoki e Lopes (1975) apresentaram uma solução de recalques para um grupo de estacas imersas em solo utilizando superposições dos efeitos das cargas por intermédio da solução de Mindlin (1936). O método leva em conta a contribuição da carga na base da estaca discretizada em subáreas $n 1$ x $n 2$, em que n1 é o número de divisões da circunferência e n2 o número de divisões do raio da base. Dessa forma, sendo $P b$ a carga total aplicada na base, as cargas aplicadas nas subáreas são dadas pela Equação 2.

$P_{i, j}=\frac{P_{b}}{n_{1} n_{2}}$ 
em que: $P_{i, j}$ - cargas aplicadas nas subáreas em que os índices i e j indicam as posições de cada subárea;

Para a contribuição do fuste, o método também prevê a divisão do perímetro da estaca em segmentos iguais, mas desta feita, considerando subdivisões do fuste (n3) em trechos associados a camadas do solo em estudo. Em cada subdivisão atua uma força $P_{i, k}$ expressa pela Equação 3.

$P_{i, k}=\frac{(D 2-D 1)}{2 n_{3}}\left[2 f_{1}-\frac{2 k-1}{n_{3}}\left(f_{1}-f_{2}\right)\right]$

em que: $f 1$ - fator de forma da parte superior das camadas do solo; $f 2$ - fator de forma da parte inferior das camadas do solo; D1- profundidade superior de cada camada de solo em relação ao topo da estaca; D2 - profundidade inferior de cada camada de solo em relação ao topo da estaca; $\mathrm{k}$ - identificador da atual camada relacionada à divisão n3 do fuste.

Através da solução de Mindlin (1936) é possível superpor os efeitos das ações das camadas de cálculo nas camadas inferiores, obtendo assim, o recalque imediato final das estacas. A referida solução considera o solo como um meio semiinfinito, homogêneo e isótropo.

O método de Poulos e Davis (1980) estendeu a metodologia proposta para a estimativa de recalques em estacas isoladas para o problema do recalque em grupo de estacas. A referida metodologia consiste em avaliar a interação entre estacas para obtenção do recalque do grupo, que para um arranjo qualquer, pode ser obtido da seguinte forma (considerando estacas com características iguais):

$w_{i}=w_{1}\left[\sum_{\substack{j=1 \\ j \neq i}}^{n}\left(Q_{j} \alpha_{i j}\right)+Q_{i}\right]$

em que: $w_{i}$ - recalque de uma estaca " $i$ " que sofre a influência de carregamento das demais estacas do grupo; $w_{1}$ - recalque da estaca isolada sob carregamento unitário; $\mathrm{Q}_{\mathrm{j}}$ - carga na estaca “j”; $\alpha_{\mathrm{ij}}$ - fator de interação entre as estacas "i”” e “j”, que é a relação entre o recalque adicional provocado por uma estaca adjacente e o recalque individual de uma estaca sob sua própria carga; $Q_{i}$ - carga de uma estaca “i” que sofre a influência de carregamento das demais estacas do grupo.

$\mathrm{O}$ fator de interação $\alpha_{\mathrm{ij}}$ é obtido em função de algumas características das estacas e do solo, a saber: diâmetro, espaçamento, rigidez da estaca e do solo, coeficiente de Poisson, espessura finita do meio, alargamento de base, variação do módulo de Young com a profundidade e presença de solo mais rígido no nível da base. Dessa forma, são encontradas "n" equações de recalques, e considerando mais uma equação de equilíbrio de forças verticais, as " $n+1$ " equações obtidas podem ser resolvidas para duas condições: a) Cargas iguais em todas as estacas do grupo e b) Recalques iguais em todas as estacas do grupo. Como destacam Velloso e Lopes (2002), verifica-se que o recalque médio de um grupo de estacas igualmente carregadas é aproximadamente igual ao recalque do grupo com o bloco do coroamento rígido. Dessa forma, a condição "a" seria mais adequada na maioria dos casos quando calculado para estacas representativas do grupo de estacas.

A NBR 6122 (2019) estabelece uma forma de tratar o efeito de grupo. A referida norma determina que a carga admissível ou força resistente de cálculo de um grupo de estacas não pode ser superior à de uma sapata hipotética definida da seguinte forma: a sapata deve ter contorno igual ao do grupo e ser considerada apoiada numa cota superior à da ponta das fundações, sendo a diferença de cotas igual a 1/3 do comprimento de penetração das fundações na camada de suporte. Dada a 
geometria imposta pela norma, pode-se empregar alguma metodologia de previsão de recalques em sapatas e assim mensurar o efeito de grupo.

\section{Metodologia}

O edifício analisado é composto por 2 torres de 20 pavimentos, em um total de sessenta metros. A lâmina dos pavimentos tipo foi projetada com 14 pilares, os quais suportam lajes nervuradas bidirecionais. A Figura 1 (a) traz o destaque do trecho do projeto geotécnico relativo aos pilares de lâmina da torre A (torre analisada). A Figura 1 (b) apresenta o pavimento tipo do edifício em que se podem identificar os pórticos formados pelos pilares e vigas. O edifício apresenta forte assimetria com respeito ao posicionamento dos pilares, com o Pilar P7 possuindo destacada rigidez quando comparado aos demais. No $1^{\circ}$ pavimento os pilares P4; P8; P11 e P13 não formam pórtico com nenhum outro pilar.

Figura 1 - Projeto geotécnico e forma do pavimento tipo do edifício analisado.
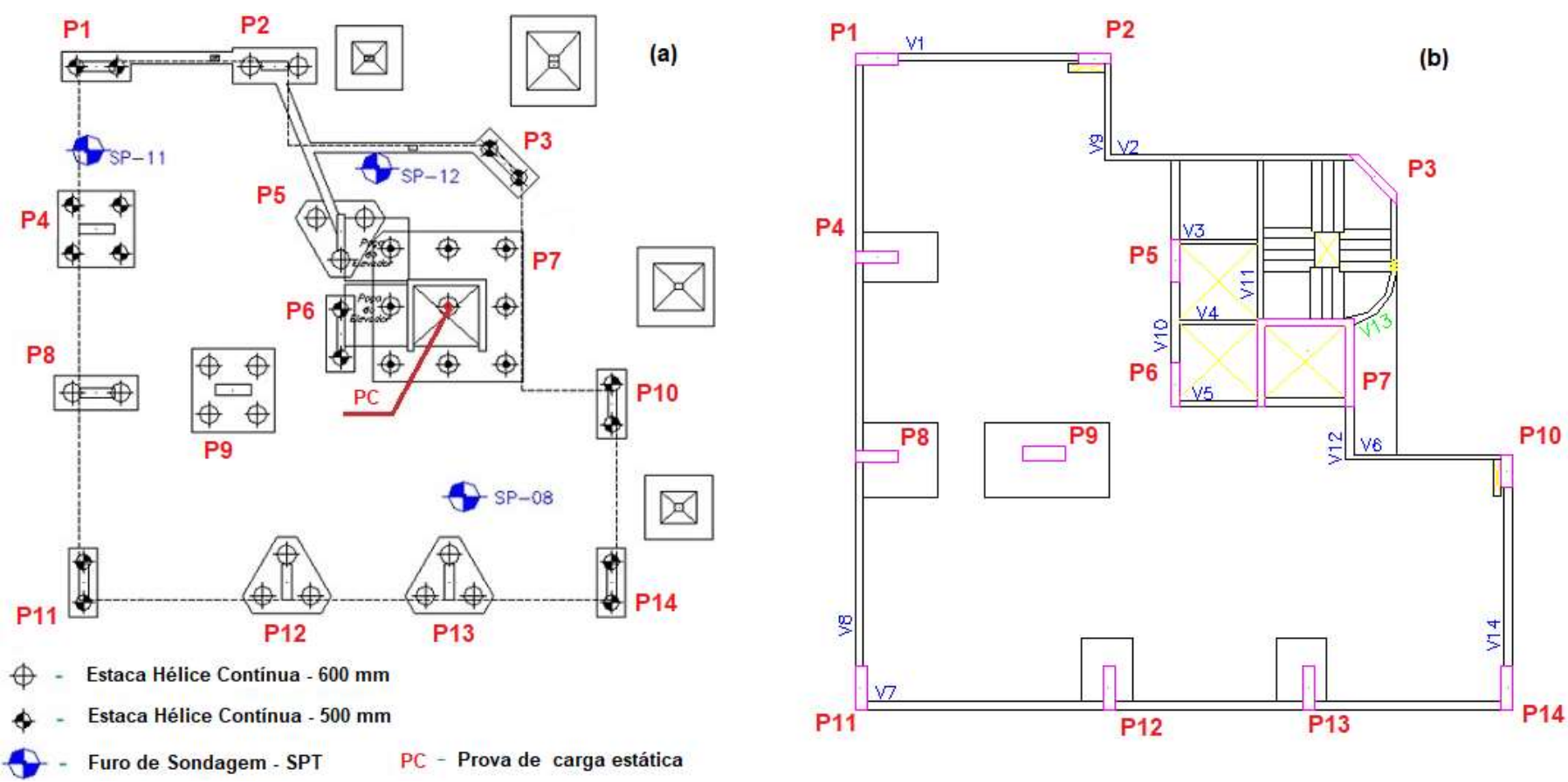

Fonte: Autores.

A solução de fundação consiste, considerando apenas a lâmina, em estacas hélice contínua em um total de 42 estacas, das quais 16 com diâmetro 500 milímetros e 26 com 600 milímetros. As cotas de ponta das estacas variaram entre 16,0 e 17,5 metros. As estacas de 500 milímetros foram projetadas com carga admissível de $1.300 \mathrm{kN}$, e as de $600 \mathrm{~mm}, 1.800 \mathrm{kN}$. O bloco com maior número de estacas corresponde ao Pilar C7, o qual possui nove estacas.

O perfil do solo (Figura 2) se apresenta bastante heterogêneo, intercalando camadas de areia siltosa e silte arenoso com $N_{S P T}$ médio de 10 golpes até os 12 metros. Em seguida, apresenta uma alta significativa na resistência no trecho de 12 a 21 metros, com $N_{S P T}$ médio de 40 golpes. A partir dos 25 metros, existe uma camada extensa de areia muito compacta, chegandose a obter índices de penetração $N_{S P T}$ de $30 / 3$. 
Figura 2 - Perfil geotécnico do edifício analisado.

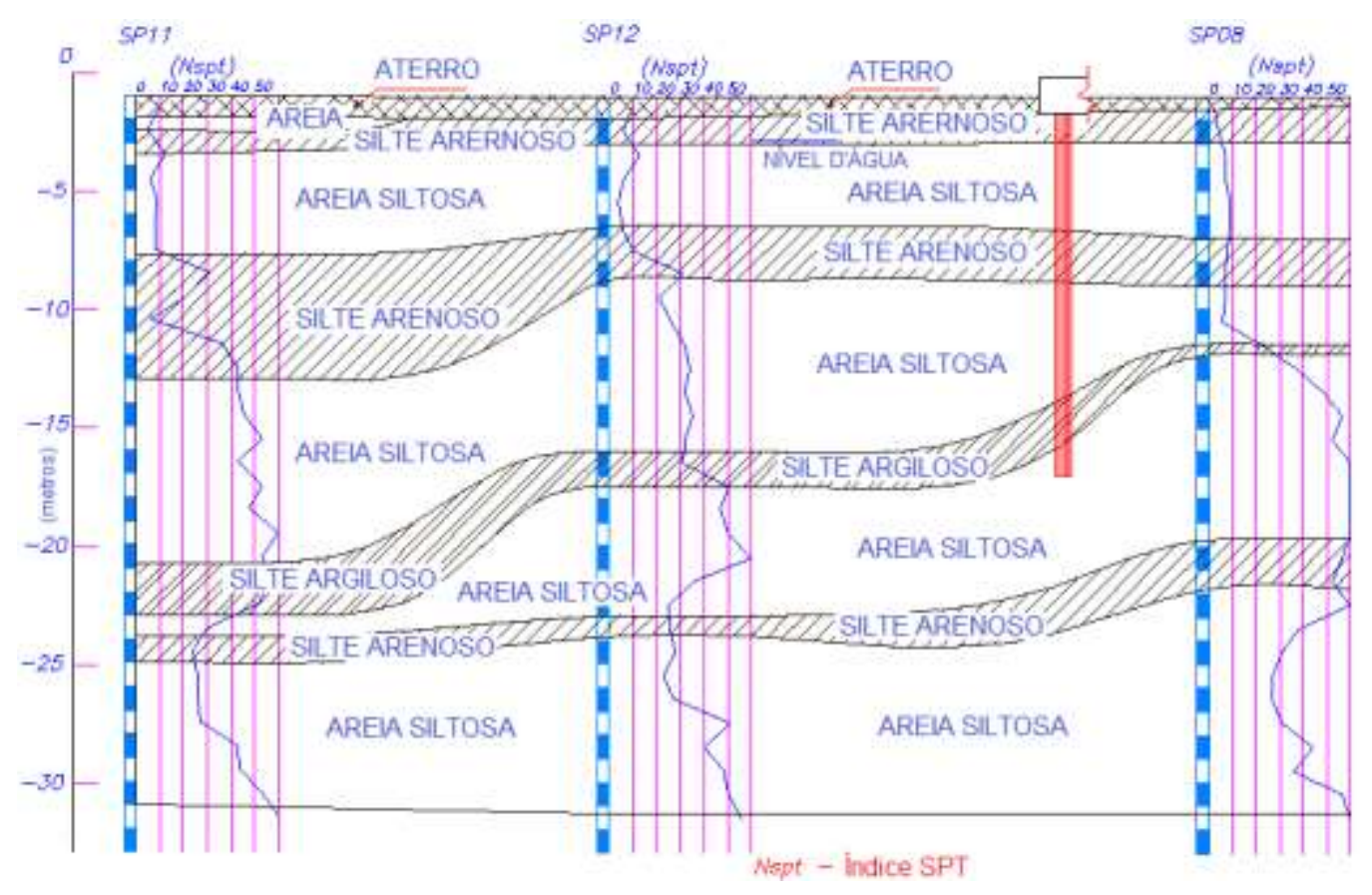

Fonte: Autores.

O edifício possui 31 etapas construtivas correspondendo a 2 anos de obra. Ressalta-se que para o referido edifício estava previsto fck de $35 \mathrm{MPa}$. Foi realizada 1 prova de carga estática na estaca central do bloco do Pilar P7 (Figura 2). As cargas de apoios indeslocáveis $V O$ foram obtidas através da consideração do EIC ao longo de 22 etapas construtivas baseadas no acompanhamento da evolução das cargas permanentes ao longo do tempo. Também foram obtidas cargas de apoios indeslocáveis sem os efeitos da EIC ( $F 0$ ). Os efeitos dependentes do tempo no concreto não foram considerados. O modelo do edifício foi realizado no programa computacional SAP 2000 (Versão 14).

Os recalques do edifício foram acompanhados por medições obtidas de pinos instalados nos pilares da lâmina, sendo as leituras realizadas com nível ótico (WILD-Na2). Os pinos foram instalados no pavimento térreo, em todos os pilares da lâmina, sendo chumbados diretamente na estrutura. Foram realizadas 5 medições de recalques (L1, L2, L3, L4 e L5), sendo a primeira leitura, L1 (realizada no $2^{\circ}$ pavimento), servindo de referência. O programa computacional SUFER Versão 13 foi utilizado para fazer interpolações de recalque e estimar valores que eventualmente não puderam ser obtidos. O referido programa foi empregado em L2 (Pilar P3); L3 (Pilares P3 e P7); L4 (Pilar P3) e L5 (Pilares P3 e P9) devido a deslocamentos acidentais do pino. Os recalques medidos, para efeito de comparação com as ISE, foram empregados como deslocamentos prescritos nos apoios dos pilares em conjunto com a EIC, de maneira que seus efeitos nos carregamentos foram denominados WO. Os valores de recalques atribuídos aos estágios em que não houve leituras de recalques foram determinados por interpolação com auxílio das cargas obtidas de cada estágio da EIC (VO). A Leitura L5, realizada quando o reservatório superior já estava executado, corresponde ao $22^{\circ}$ estágio de obra, no qual se obtiveram as cargas $V O$ e $W O$. A Tabela 1 apresenta as 22 etapas construtivas de EIC empregadas na análise, assim como o tempo acumulado e a laje construída equivalente ao estágio em que se encontrava a

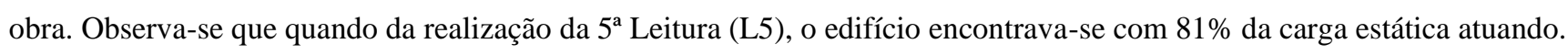


Tabela 1 - Estágios considerados para modelagem do Efeito Incremental Construtivo (EIC).

\begin{tabular}{|c|c|c|}
\hline $\begin{array}{c}\text { Etapa } \\
\text { Construtiva }\end{array}$ & $\begin{array}{c}\text { Tempo } \\
\text { acumulado (dias) }\end{array}$ & Observação \\
\hline 1 & 28 & $1^{\mathrm{a}} \mathrm{LAJE}$ \\
\hline 2 & 45 & 1 $^{\text {a }}$ LEITURA (L1) / $2^{\text {a }}$ LAJE \\
\hline 3 & 56 & $2^{\mathrm{a}} \mathrm{LAJE}$ \\
\hline 4 & 84 & $2^{\mathrm{a}} \mathrm{LAJE}$ \\
\hline 5 & 112 & $3^{\mathrm{a}}$ e $4^{\mathrm{a}} \mathrm{LAJE}$ \\
\hline 6 & 129 & $2^{\mathrm{a}}$ LEITURA (L2) / $5^{\mathrm{a}}$ e $6^{\mathrm{a}}$ LAJE \\
\hline 7 & 140 & $7^{\mathrm{a}} \mathrm{LAJE}$ \\
\hline 8 & 168 & $8^{\mathrm{a}} ; 9^{\mathrm{a}}$ e $10^{\mathrm{a}} \mathrm{LAJE}$ \\
\hline 9 & 196 & $11^{\mathrm{a}} ; 12^{\mathrm{a}}$ e $13^{\mathrm{a}} \mathrm{LAJE}$ \\
\hline 10 & 213 & $3^{\mathrm{a}}$ LEITURA (L3) / $14^{\mathrm{a}} ; 15^{\mathrm{a}}$ e $16^{\mathrm{a}}$ LAJE \\
\hline 11 & 224 & $17^{\mathrm{a}} \mathrm{LAJE}$ \\
\hline 12 & 252 & $18^{\mathrm{a}} ; 19^{\mathrm{a}}$ e $20^{\mathrm{a}} \mathrm{LAJE}$ \\
\hline 13 & 280 & RESERVATÓRIO \\
\hline 14 & 308 & RESERVATÓRIO \\
\hline 15 & 325 & 4 ${ }^{\text {a }}$ LEITURA (L4) / RESERVATÓRIO \\
\hline 16 & 336 & RESERVATÓRIO \\
\hline 17 & 364 & RESERVATÓRIO \\
\hline 18 & 392 & RESERVATÓRIO \\
\hline 19 & 420 & RESERVATÓRIO \\
\hline 20 & 448 & RESERVATÓRIO \\
\hline 21 & 476 & RESERVATÓRIO \\
\hline 22 & 504 & 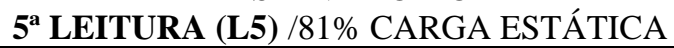 \\
\hline
\end{tabular}

Fonte: Autores.

A Figura 3 apresenta as curvas de isorecalques compostas pelos recalques medidos. Observa-se na leitura L5 que o maior recalque é da ordem de 10,50 mm, correspondente ao Pilar P7, ao passo que o menor é 5,99 mm, correspondente ao Pilar P12. Apesar das leituras de recalque começarem a ser medidas efetivamente na segunda leitura (L2), optou-se por não corrigir as medições de recalque, pois as regressões lineares aplicadas aos pilares P5; P7 e P9 apresentaram um poder de explicação (Rquadrado) de $76 \%$; 68\% e 69\%, respectivamente, o que indica que somente o carregamento (variável independente), não explica o comportamento dos recalques (variável dependente) na regressão.

Os recalques estimados foram calculados pelo método empírico de Meyerhof (1959), pelos métodos elásticos de Aoki e Lopes (1975) e Poulos e Davis (1980) e pelo método da norma brasileira NBR 6122 (2019). Para a utilização do método de Meyerhof (1959), as cargas foram dividas pelo número de estacas em cada pilar. De posse desse resultado, foram determinados os recalques individuais das estacas em cada pilar com o auxílio da prova de carga realizada em estaca pertencente ao Pilar P7. Finalmente, aplicou-se a Equação 1 para encontrar os recalques de grupo. O método de Aoki e Lopes (1975) utilizou o método semiempírico de Antunes e Cabral (1996) aos furos de sondagem (Figura 2) para determinar as incógnitas presentes nas Equações 2 e 3. Na interação entre estacas $\left(\alpha_{\mathrm{ij}}\right)$ do método de Poulos e Davis (1980), foi considerado um fator de rigidez $(\mathrm{K})$ de 1.000, sendo corrigido em função do coeficiente de Poisson de acordo com o que preconiza o referido método. O recalque da estaca isolada sob carregamento unitário $\left(\mathrm{w}_{1}\right)$ também foi obtido com o auxílio da prova de carga realizada. O meio em que se inserem as estacas foi considerado como semi-infinito. 
Figura 3 - Curvas de isorecalques obtidas das leituras L2 a L5.
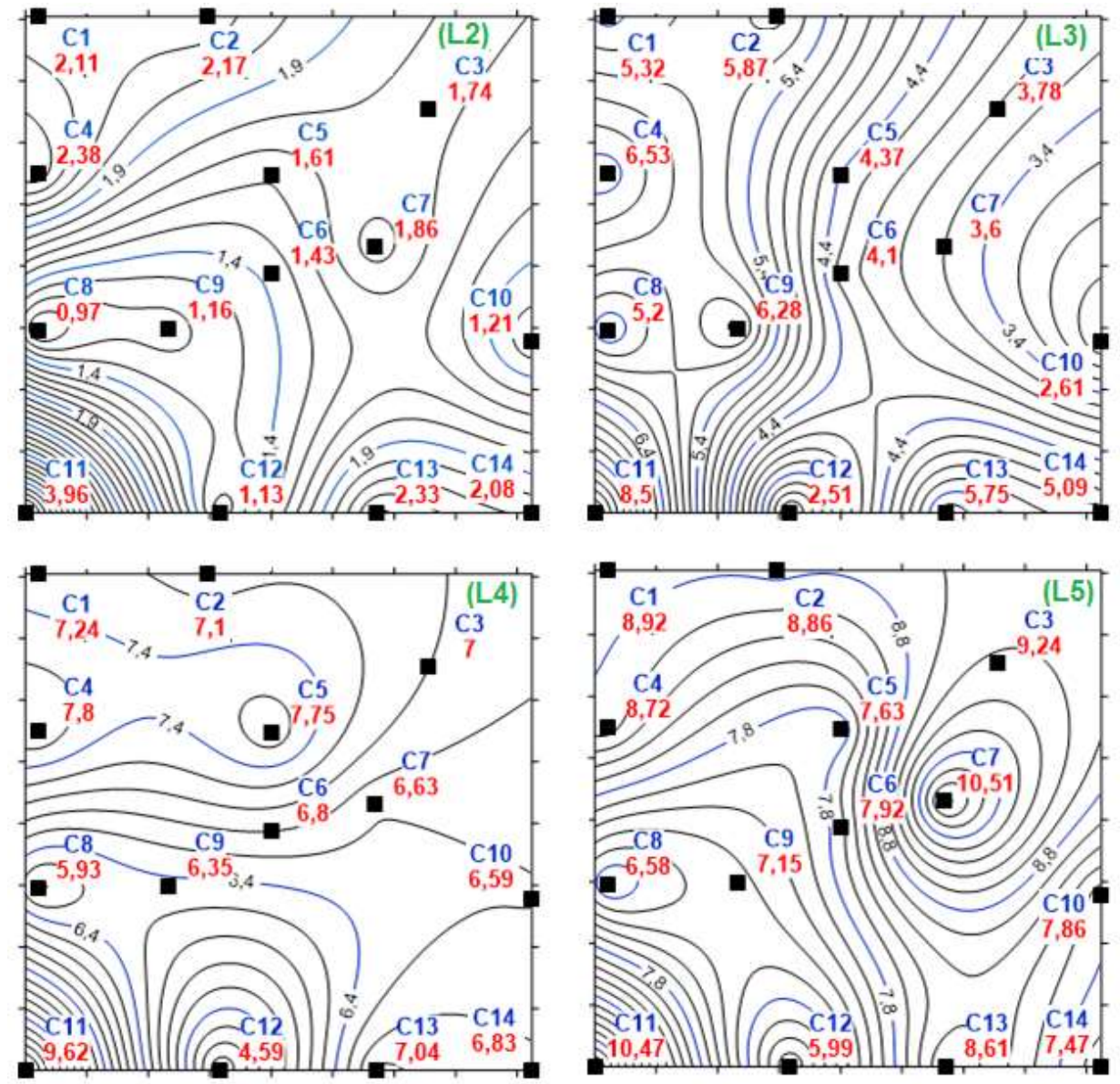

- Pilares com a indicação de recalques em milímetros (em vermelho)

L2; L3; L4; L5 - Leituras de recalques

Fonte: Autores.

O método da NBR 6122 (2019), foi utilizado em conjunto com o método de Schmertmann (1978). A Tabela 2 resume os dados utilizados para encontrar os recalques com o referido método. Os valores de peso específico das camadas de solo foram obtidos de Das e Sobhan (2014) e o módulo de deformabilidade Es de Teixeira e Godoy (1996), o qual substitui a resistência de ponta da formulação original $q c$ pelos índices $\mathrm{K}$ e $\mathrm{N}_{\mathrm{SPT}}$, de maneira que:

$E s=\alpha \cdot K \cdot N_{S P T}$

em que $\alpha$-coeficiente dado em função do solo; $K$ - coeficiente empírico que corrige o valor de $q c$ em função do $\mathrm{N}_{\mathrm{SPT}}$.

As cargas $F 0$ foram empregadas em conjunto com os referidos métodos, servindo de ponto de partida para realização de ISE até obtenção de convergência mínima de 5,0 kN. As cargas advindas de ISE foram denominadas de acordo com o método de recalque empregado: ISE associada ao método de Meyerhof (1959) - $V_{M E Y}$; ISE associada ao método de Aoki e Lopes (1975) - $V_{A O L}$; ISE associada ao método de Poulos e Davis (1980) - $V_{P L D}$ e ISE associada ao método da norma brasileira NBR 6122 (2019) - $V_{N B R}$. Comparações foram realizadas em termos de relações entre cargas VO e FO; WO e FO; assim como entre cargas de ISE $\left(V_{M E Y} ; V_{A O L} ; V_{P L D}\right.$ e $\left.V_{N B R}\right)$ e $F O$. 
Tabela 2 - Dados empregados para o cálculo de recalques por Schmertmann (1978).

\begin{tabular}{ccccc}
\hline $\begin{array}{c}\text { Bloco de } \\
\text { Coroamento }\end{array}$ & $\mathbf{B}^{(\mathbf{a})}(\mathbf{m})$ & $\mathbf{L}^{(\mathbf{b})}(\mathbf{m})$ & $\mathbf{q}^{(\mathbf{c})}(\mathbf{k P a})$ & $\boldsymbol{\sigma}^{* \mathbf{d}}(\mathbf{k P a})$ \\
\hline P1 & 0,50 & 1,76 & 123,22 & $1.789,04$ \\
P2 & 0,60 & 2,10 & 97,14 & $1.589,84$ \\
P3 & 0,50 & 1,76 & 97,14 & $1.794,41$ \\
P4 & 2,00 & 2,00 & 123,22 & 569,65 \\
P5 & 1,50 & 1,50 & 97,14 & $1.215,96$ \\
P6 & 0,50 & 1,76 & 97,14 & $2.449,70$ \\
P7 & 4,20 & 4,20 & 97,14 & 218,54 \\
P8 & 0,60 & 2,10 & 123,22 & $2.063,83$ \\
P9 & 2,10 & 2,10 & 97,14 & 753,21 \\
P10 & 0,50 & 1,76 & 97,14 & $1.838,43$ \\
P11 & 0,50 & 1,76 & 97,14 & $2.008,34$ \\
P12 & 1,50 & 1,50 & 97,14 & $1.310,74$ \\
P13 & 1,50 & 1,50 & 97,14 & $1.036,24$ \\
P14 & 0,50 & 1,76 & 97,14 & $2.108,85$ \\
\hline
\end{tabular}

(a) Menor dimensão da sapata hipotética; (b) Maior dimensão da sapata hipotética; (c) Tensão vertical efetiva aplicada na cota de apoio da sapata hipotética; (d) Tensão líquida aplicada pela sapata hipotética. Fonte: Autores.

Realizou-se comparação entre os momentos junto aos pilares do pórtico P1; P4; P8 e P11; do pórtico P5 e P6 e do pórtico P11; P12; P13 e P14 até o $8^{\circ}$ pavimento. Os momentos advindos de ISE foram denominados de acordo com o método de recalque empregado: ISE associada ao método de Meyerhof (1959) - $M_{M E Y}$; ISE associada ao método de Aoki e Lopes (1975) - $M_{A O L}$; ISE associada ao método de Poulos e Davis (1980) - $M_{P L D}$ e ISE associada ao método da norma brasileira NBR 6122 (2019) - $M_{N B R}$. Os momentos associados ao modelo de apoios indeslocáveis sem consideração de EIC foi denominado $M F O$. Os momentos associados ao modelo de apoios indeslocáveis com consideração de EIC foi denominado MVO. Os momentos associados ao modelo de apoios indeslocáveis com consideração de EIC e deslocamentos prescritos foi denominado MWO. Comparações foram realizadas em termos de relações entre momentos $M V O$ e $M F 0 ; M W O$ e $M F 0$; assim como entre os momentos de ISE ( $M_{M E Y} ; M_{A O L} ; M_{P L D}$ e $M_{N B R}$ ) e $M F O$.

\section{Resultados e Discussão}

Os recalques estimados pelos diferentes métodos, o resultado das cargas F0, V0, W0 e das ISE são apresentados na Tabela 3. Destaca-se a grande variabilidade de medidas de recalque obtidas. O pilar P6, por exemplo, que possui bloco com 2 estacas, teve um recalque medido de 7,92 $\mathrm{mm}$ (Figura 3 - L5), ao passo que as previsões de recalque dos diferentes métodos variaram de 4,37 $\mathrm{mm}$ a 23,60 $\mathrm{mm}$ para o referido pilar. A variabilidade detectada é resultado da natureza de cada metodologia. O método de Meyerhof (1959) leva apenas em conta a geometria dos blocos e a relação entre espaçamento e diâmetro. O método de Poulos e Davis (1980) é dependente de uma série de coeficientes, entre eles, a relação entre módulo de elasticidade da estaca e do solo, que quando não são adequadamente conhecidos, incorporam essas incertezas nas estimativas de recalque. De maneira similar, o método da NBR 6122 (2019), o qual está associado, nesse estudo, ao método de Schmertmann (1978), assim como o método de Aoki e Lopes (1975) são normalmente dependentes de correlações, como a do módulo de elasticidade do solo, o qual tem grande impacto no cálculo dos recalques. No Brasil o índice $\mathrm{N}_{\mathrm{SPT}}$ é geralmente utilizado para emprego de correlações em detrimento ao CPT. As referidas correlações são realizadas com formulações que muitas vezes ignoram aspectos da natureza do solo, como a densidade das areias, por exemplo, a qual tem grande influência nessa correlação (Souza, Danziger \& Danziger, 2012). 
Tabela 3 - Resumo de recalques e cargas nos apoios dos pilares.

\begin{tabular}{|c|c|c|c|c|c|c|c|c|c|c|c|}
\hline $\begin{array}{c}\text { Pil } \\
\text { (a) }\end{array}$ & $\begin{array}{c}\operatorname{Rec} \\
\mathrm{MEY} \\
(\mathbf{m m}) \\
(\mathbf{b})\end{array}$ & $\begin{array}{c}\text { Rec } \\
\text { AOL } \\
(\underset{(\mathbf{m m})}{(\mathbf{c})})\end{array}$ & $\begin{array}{c}\text { Rec } \\
\text { PLD } \\
\left(\begin{array}{c}\text { (mm) } \\
\text { (d) }\end{array}\right.\end{array}$ & $\begin{array}{c}\operatorname{Rec} \\
\text { NBR } \\
(\mathbf{m m}) \\
(\mathbf{e})\end{array}$ & $\begin{array}{c}\text { F0 } \\
(\mathbf{k N}) \\
(\mathbf{f})\end{array}$ & $\begin{array}{c}\mathbf{V 0} \\
(\mathbf{k N}) \\
(\mathrm{g})\end{array}$ & $\begin{array}{c}\text { W0 } \\
(\mathbf{k N}) \\
(\mathbf{h})\end{array}$ & $\begin{array}{c}V_{\text {MEY }} \\
(\mathbf{k N}) \\
(\mathbf{i})\end{array}$ & $\begin{array}{c}\mathbf{V}_{\text {AOL }} \\
(\mathbf{k N}) \\
(\mathbf{j})\end{array}$ & $\begin{array}{c}\text { VPLD } \\
(\mathbf{k N}) \\
(\mathbf{k})\end{array}$ & $\begin{array}{c}\mathbf{V}_{\text {NBR }} \\
(\mathbf{k N}) \\
\text { (l) }\end{array}$ \\
\hline P1 & 3,45 & 3,77 & 3,37 & 10,01 & 1885 & 1791 & 1686 & 2037 & 1911 & 1934 & 2349 \\
\hline P2 & 3,51 & 3,52 & 4,25 & 16,31 & 2091 & 2064 & 2134 & 2081 & 2079 & 2132 & 1399 \\
\hline P3 & 3,73 & 3,71 & 3,33 & 15,97 & 1776 & 1713 & 1677 & 1721 & 1703 & 2056 & 682 \\
\hline P4 & 5,84 & 4,15 & 4,42 & 6,12 & 2829 & 2843 & 2753 & 2673 & 2884 & 2853 & 3795 \\
\hline P5 & 5,58 & 4,20 & 5,34 & 18,75 & 2479 & 2528 & 2921 & 2281 & 2537 & 2401 & 233 \\
\hline P6 & 6,63 & 5,39 & 4,37 & 23,60 & 2004 & 1899 & 2336 & 1384 & 1468 & 2736 & 0 \\
\hline P7 & 4,03 & 3,54 & 7,15 & 4,60 & 6947 & 6773 & 5495 & 7643 & 7413 & 5702 & 1235 \\
\hline P8 & 5,46 & 5,24 & 5,51 & 14,21 & 2661 & 2606 & 2773 & 2714 & 2526 & 2531 & 2324 \\
\hline P9 & 5,18 & 4,26 & 6,27 & 14,42 & 3643 & 3632 & 3741 & 3725 & 3713 & 3516 & 3381 \\
\hline P10 & 4,76 & 4,43 & 3,41 & 12,33 & 1701 & 1673 & 1697 & 1666 & 1611 & 1887 & 1461 \\
\hline P11 & 5,38 & 4,45 & 3,71 & 13,78 & 2174 & 2077 & 1838 & 2350 & 2275 & 2345 & 2355 \\
\hline P12 & 7,69 & 4,74 & 5,73 & 15,16 & 2992 & 3002 & 3178 & 2740 & 2947 & 2859 & 2640 \\
\hline P13 & 5,56 & 4,13 & 4,61 & 11,33 & 2682 & 2684 & 2543 & 2834 & 2741 & 2753 & 3031 \\
\hline P14 & 5,75 & 4,39 & 3,88 & 14,65 & 1792 & 1730 & 1953 & 1729 & 1782 & 1874 & 1223 \\
\hline
\end{tabular}

(a) Pilar; (b) Recalque estimado por Meyerhof (1959); (c) Recalque estimado por Aoki e Lopes (1975); (d) Recalque estimado por Poulos e Davis (1980); (e) Recalque estimado pela NBR 6122 (2019); (f) Cargas advindas de apoios indeslocáveis; (g) Cargas advindas da EIC com apoios indeslocáveis; (h) Cargas advindas da EIC com apoios indeslocáveis e deslocamento prescrito; (i) Interação solo estrutura com os recalques de rec $\mathrm{MEY}$; ; (j) Interação solo estrutura com os recalques de rec $\mathrm{AOL}_{\text {; }}$ (k) Interação solo estrutura com os recalques de rec $\mathrm{PLD}_{\text {; }}$ (l) Interação solo estrutura com os recalques de recnBR; Fonte: Autores.

Para visualizar o efeito das ISE em comparação ao modelo de cargas com apoios indeslocáveis $F 0$, apresenta-se a Figura 4, a qual ilustra as relações $V_{M E Y} / F O, V_{A O L} / F O, V_{P L D} / F O, V_{N B R} / F O$ e $V 0 / F O$. Em todas as comparações também está presente a relação WO/FO. A relação WO/VO revela que o Pilar P6 aumentou a carga em 17\%, enquanto o Pilar P11 diminuiu 15\%. Com o método da NBR 6122 (2019), o Pilar P7 chega a aumentar a carga em 80\% ao mesmo tempo em que a carga Pilar P6 fica igual a zero. Quando se considera Meyerhof (1959), o Pilar P7 tem um aumento de carga de 10\% ao passo que o Pilar P6 diminui 31\% de sua carga. Considerando o método de Aoki e Lopes (1975), o Pilar P7 tem aumento de carga de 7\% enquanto o Pilar P6 tem diminuição de 27\%. Já quando considerado o método de Poulos e Davis (1980) o Pilar P7 apresenta $18 \%$ de redução enquanto o pilar P6 tem um aumento de 37\%. A comparação com o modelo que considera apenas o EIC (V0/F0) revela que ambos os pilares, P7 e P6, têm redução de carregamento de $2 \%$ e 5\%, respectivamente. É interessante notar que alguns pilares apresentaram comportamento contrário ao esperado quando empregada a interação solo estrutura, pois quando considerado o referido mecanismo, a expectativa é que pilares centrais diminuam sua carga ao passo que os pilares periféricos aumentem sua carga (Gusmão, 1994; Danziger, Costa \& Danziger, 2005). Esses resultados podem ser creditados à magnitude dos recalques e ao formato da estrutura, pois como observado por Lopes e Gusmão (1991), o formato da planta baixa do edifício também exerce influência na rigidez relativa estrutura-solo.

$\mathrm{Na}$ mesma figura (Figura 4) estão também indicados na parte superior direita os coeficientes de variação (CV) das relações entre cargas dos diversos modelos. Observa-se como os valores de recalque, com suas consequências nos resultados da ISE, influenciam na dispersão em relação aos valores médios das relações de carga de cada método. Os métodos de Aoki e Lopes (1975), Meyerhof (1959) e Poulos e Davis (1980), apresentaram valores de CV de 8,17\%; 10,47\% e 12,01\%, respectivamente, apresentando uma dispersão próxima entre si. O método da NBR 6122 (2019) apresentou uma dispersão de $56,01 \%$ se destacando em relação aos demais métodos. A variabilidade de CV detectada é função da natureza de cada metodologia, como discutido anteriormente. A relação $V 0 / F O$ apresentou uma dispersão de 2,29\%. Era esperado que a referida relação apresentasse a menor dispersão, uma vez que seus apoios são indeslocáveis, não estando submetidas à variabilidade dos recalques. A dispersão da relação W0/F0, que é o modelo que integra o EIC e os deslocamentos prescritos, foi de 11,08\%. 
Figura 4 - Relações de carga entre os diversos modelos e apoio indeslocável $(F O)$ com escalas diferentes em Y.
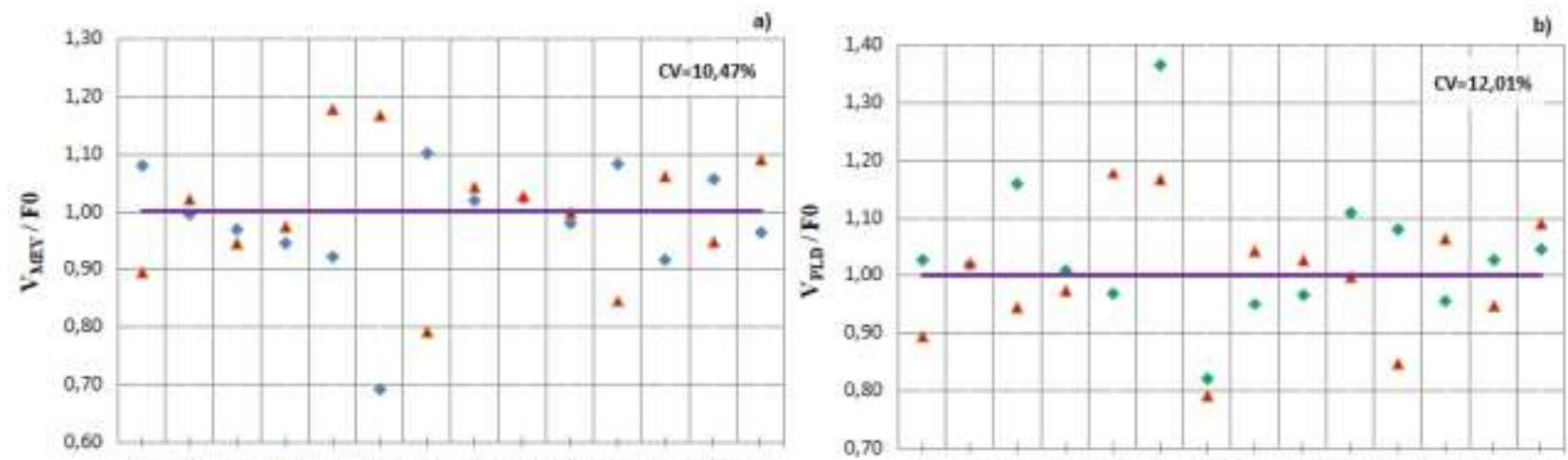

$\begin{array}{llllllllllllll}P 1 & P 2 & P 3 & P 4 & P 5 & P 6 & P 7 & P 8 & P 9 & P 10 & P 11 & P 12 & P 13 & P 14\end{array}$

0,70

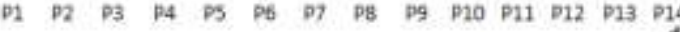
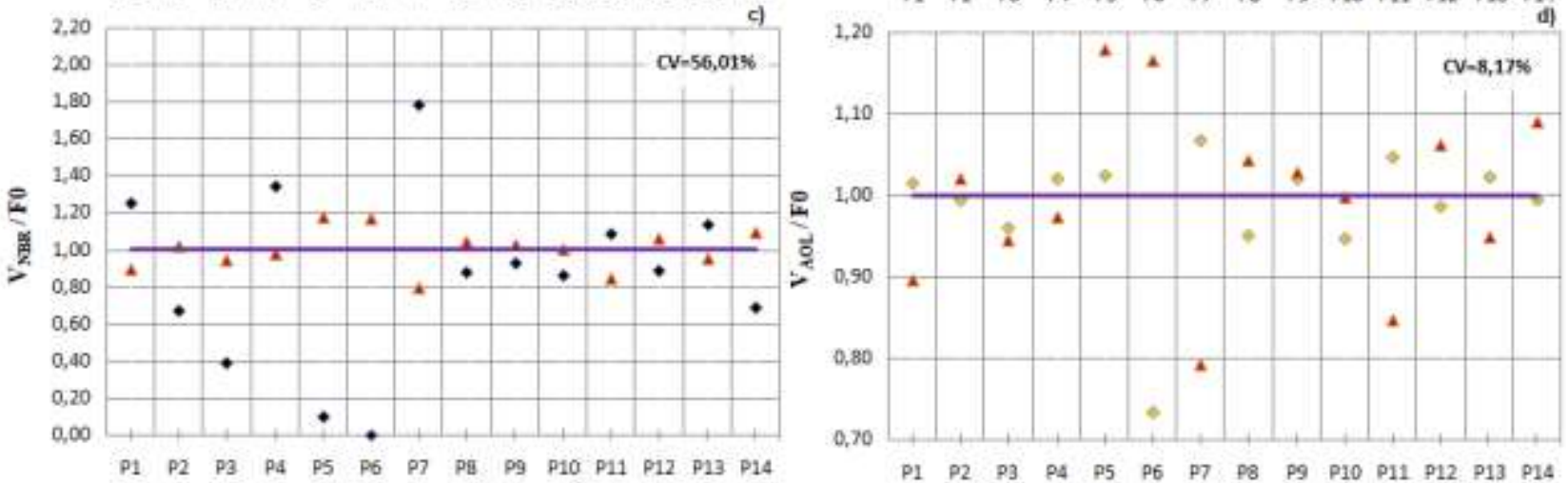

$\begin{array}{llllllllllllll}P 1 & P 2 & P 3 & P 4 & P 5 & P 6 & P 7 & P 8 & P 9 & P 10 & P 11 & P 12 & P 13 & P 14\end{array}$

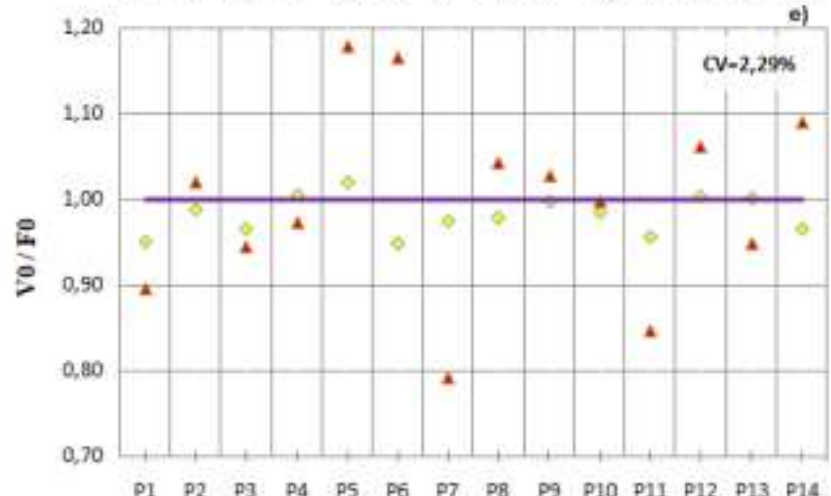

Fo - Carga de apoio indeslocável sem a consideraçào de Efeilo Incremental Construtivo (EIC)

CV - Coeficiente de Variaçä̀o dos dados de cada modelo

- VMEY - Carga obtida da interação solo estrutura com recalques estimados por Meyerhof (1959) - dividida por F0

VPL - Carga obtida da interação solo estrutura com recalques estimados por Poulos a Davis (1980) - dividida por F0

Vkan - Carga obtida da interação solo estrutura com recalques

estimados pela NBR 6122 (2019) - dividida por FO

VAOL - Carga obtida da interaçào solo estrutura com recalques estimados por Aoki e Lopes (1975) - dividida por F0

V0 - Carga obtida do Efeito incremental Construtivo (EIC) considerando os apoios como indeslocáveis - dividida por $F 0$

Wo - Carga obtida do Eleito Incremental Construtivo (EIC) considerando destocamentos prescritos - dividida por Fo

Fonte: Autores.

A Figura 5 apresenta a comparação de momentos próximos aos pilares do pórtico formado por P1; P4; P8 e P11. Observa-se a variabilidade de intensidade de momentos em cada método com respeito ao modelo que considera os pilares indeslocáveis. O Pilar P4, por exemplo, apresenta a maior variação quando comparado aos demais. Quando considerado o método de Meyerhof (1959), o momento no Pilar P4 é 13 vezes maior e com sinal invertido no $2^{\circ}$ teto. Com o método de Aoki e Lopes (1975), o momento no Pilar P4 é 6 vezes maior no $2^{\circ}$ teto. Com o método de Poulos e Davis (1980), seu momento é 3 vezes maior no $2^{\circ}$ teto. Com o método da NBR 6122 (2019), seu momento é 62 vezes maior no $2^{\circ}$ teto. No modelo em que se considera somente o EIC $\left(\mathrm{M}_{\mathrm{v} 0} / \mathrm{M}_{\mathrm{F} 0}\right)$, é cerca de $10 \%$ maior. Já no modelo em que se considera EIC e deslocamento prescrito é 14 vezes maior e com sinal invertido. 
Figura 5 - Comparação de momentos no pórtico P1; P4; P8 e P11 com escalas diferentes em Y.
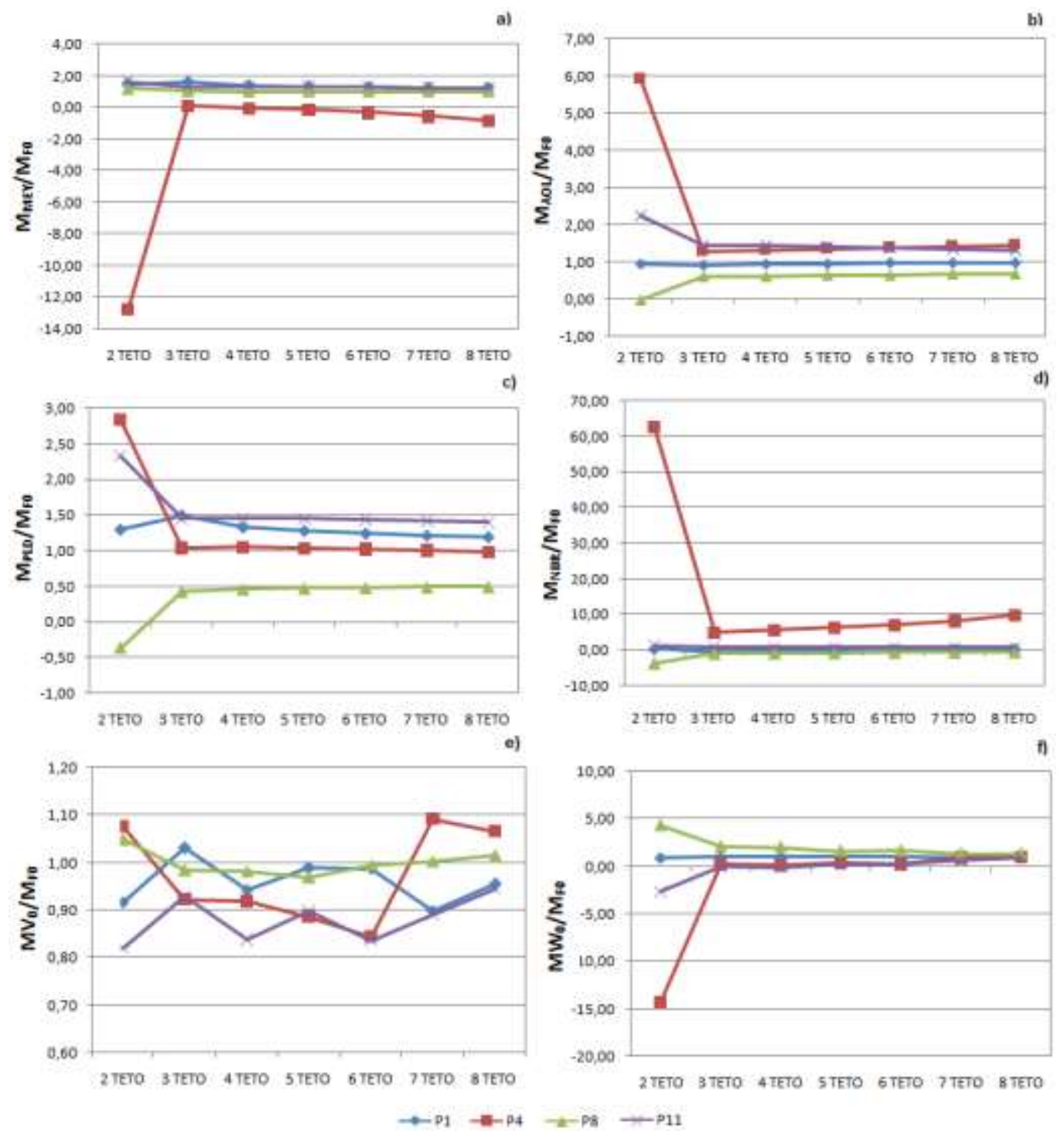

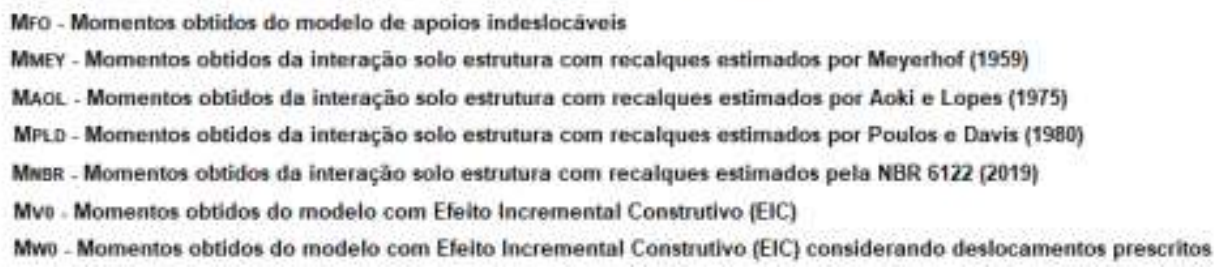

Fonte: Autores.

A Figura 6 apresenta a comparação de momentos próximos aos pilares do pórtico formado pelos pilares P5 e P6. Mais uma vez verifica-se a variabilidade de intensidade de momentos em cada método com respeito ao modelo que considera os pilares indeslocáveis. O Pilar P5, por exemplo, apresenta a maior variação quando comparado ao Pilar P6. Quando considerado o método de Meyerhof (1959), o momento no Pilar P5 é 20 vezes maior e com sinal invertido no $2^{\circ}$ teto. Com o método de Aoki e Lopes (1975), o momento no Pilar P5 é 40 vezes maior no $2^{\circ}$ teto e com sinal invertido. Com o método de Poulos e Davis (1980), seu momento é 35 vezes maior no $2^{\circ}$ teto. Com o método da NBR 6122 (2019), seu momento é 160 vezes maior no $2^{\circ}$ teto. No modelo em que se considera somente o EIC $\left(\mathrm{M}_{\mathrm{V} 0} / \mathrm{M}_{\mathrm{F} 0}\right)$, é cerca de 5 maior e com sinal invertido. Já no modelo em que se considera EIC e deslocamento prescrito é 20 vezes maior e com sinal invertido. 
Research, Society and Development, v. 10, n. 9, e42810918199, 2021

(CC BY 4.0) | ISSN 2525-3409 | DOI: http://dx.doi.org/10.33448/rsd-v10i9.18199

Figura 6 - Comparação de momentos no pórtico P5 e P6 com escalas diferentes em Y
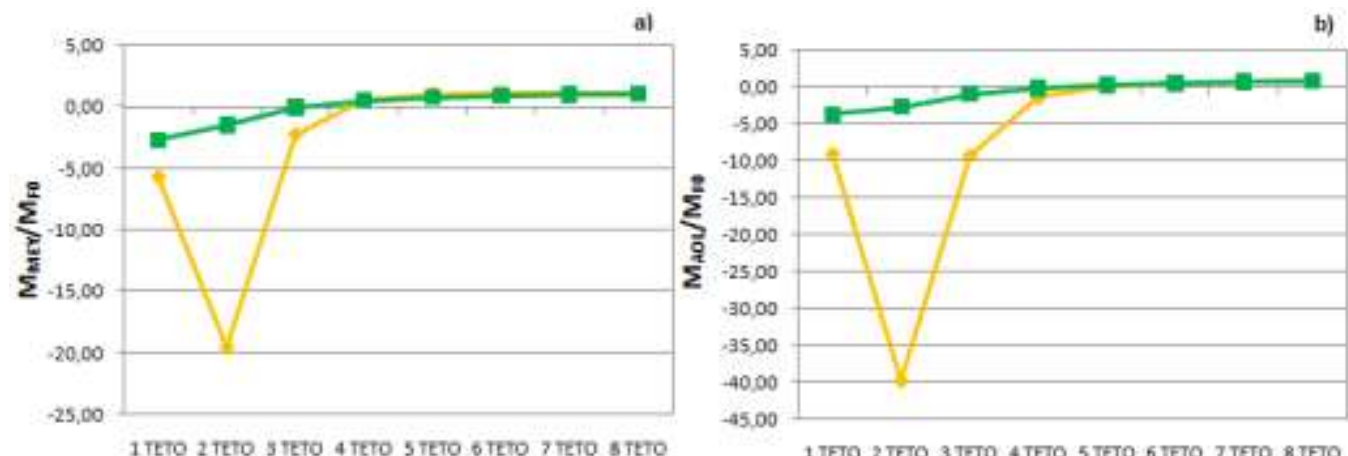

c)
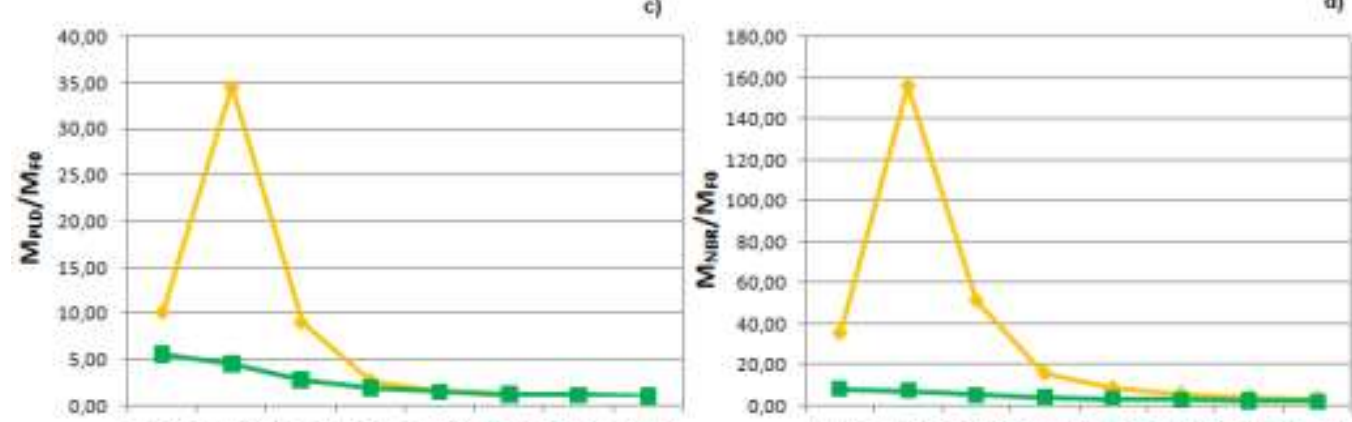

1TETO 2 TETO 3 TETO 4 TETO 5 TETO 6 TETO 7 TETO B TETO

1TETO 2TETO 3 TETO 4 TETO 5 TETO 6 TETO 7 TETO \& TETO
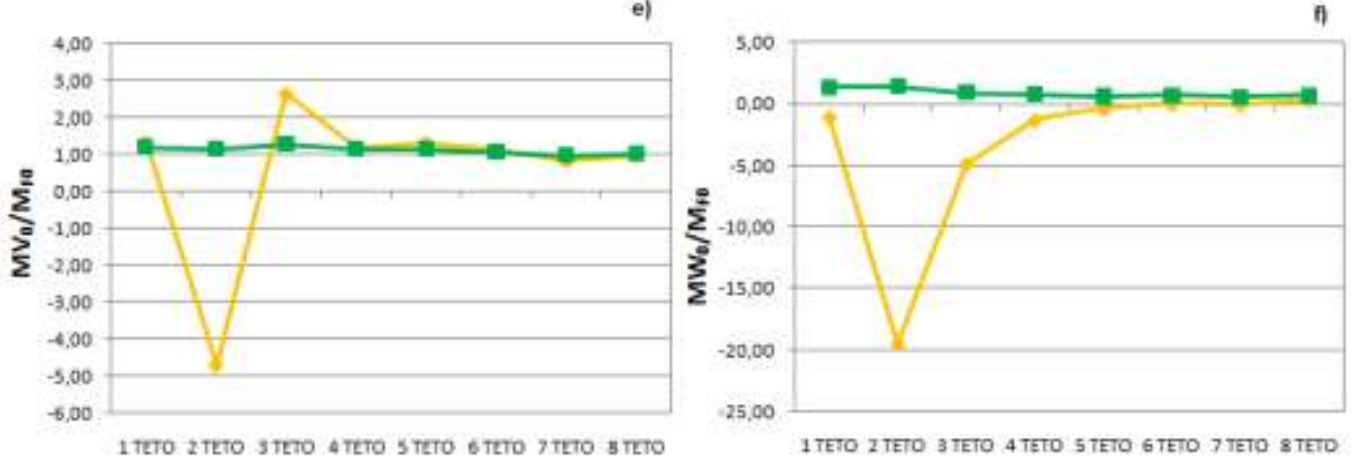

$\rightarrow-P 5 \rightarrow-P 6$

Mro - Momentos obtidos do modelo de apoios indeslocáveis

MMEY - Momentos obtidos da interaçào solo estrutura com recalques estimados por Meyerhof (1959)

MaOL. Momentos obtidos da iateraçalo solo estrutura com recalques estimados por Aoki e Lopes (1975)

MpL. D - Momentos obtidos da interaçăo solo estrutura com recalques estimados por Poulos e Davis (1980)

MuER - Monentos ottidos da interaçào solo estrutura com recalques estimados pela NBR 6122 [2019]

Mvo - Momentos obtidos do modelo com Efeito Incremental Construtivo (EIC)

Mwo - Momentos obtidos do modelo com Efeito Incremental Construtivo (EIC) considerando deslocamentos prescritos

Fonte: Autores.

A Figura 7 apresenta a comparação de momentos próximos aos pilares do pórtico formado pelos pilares P11; P12; P13 e P14. Mais uma vez verifica-se a variabilidade de intensidade de momentos em cada método com respeito ao modelo que considera os pilares indeslocáveis. O Pilar P13, por exemplo, apresenta a maior variação quando comparado aos demais. Quando considerado o método de Meyerhof (1959), o momento no Pilar P13 é 40 vezes maior e com sinal invertido no $2^{\circ}$ teto. Com o método de Aoki e Lopes (1975), o momento no Pilar P13 é 13 vezes maior e com sinal invertido no $2^{\circ}$ teto. Com o método de Poulos e Davis (1980), seu momento é 8 vezes maior e com sinal invertido no $2^{\circ}$ teto. Com o método da NBR 6122 (2019), seu momento é 113 vezes maior e com sinal invertido no $2^{\circ}$ teto. No modelo em que se considera somente o EIC $\left(\mathrm{M}_{\mathrm{V} 0} / \mathrm{M}_{\mathrm{F} 0}\right)$, é cerca de $20 \%$ menor. Já no modelo em que se considera EIC e deslocamento prescrito é 74 vezes maior. 
Figura 7 - Comparação de momentos no pórtico P11; P12; P13 e P14 com escalas diferentes em Y.
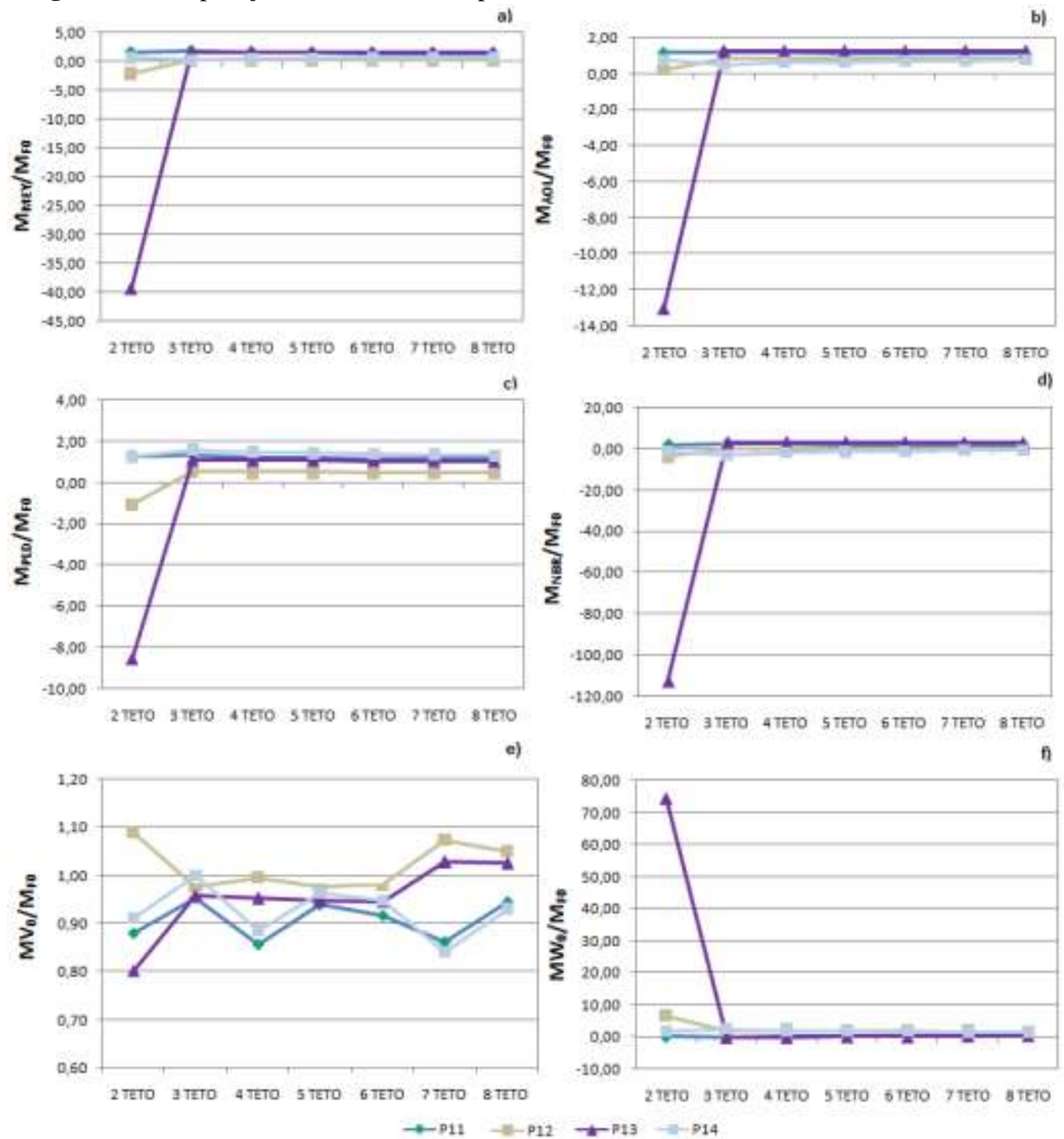

\footnotetext{
Mro - Momentos obtidos do modelo de apoios indeslocáveis

Mmer - Mornentos obtidos da interaçào solo estrutura com recalques estimados por Meyerhof (1959)

MaOL. Momentos obtidos da interaçbo solo estrutura com recalques estimados por Aoki e Lopes (1975)

MPL - Momentos obtidos da interaçào solo estrutura com recalques estimados por Poulos e Davis (1980)

MuHR - Momentos obtidos da interaçào solo estrutura com recalques estimados pela NBR 6122 (2019)

Mvo - Momentos obtidos do modelo com Eleito Incremental Construtivo (EIC)

Mwo - Momentos obtidos do modelo com Efeito Incremental Construtivo (EIC) considerando deslocamentos prescritos
}

Fonte: Autores.

A variabilidade detectada nas Figuras 5; 6 e 7, no caso dos métodos de Meyerhof (1959), Aoki e Lopes (1975), Poulos e Davis (1980) e da NBR 6122 (2019) é devida à rigidez das molas obtidas em função da estimativa dos recalques, assim como da rigidez da própria estrutura. Os momentos fletores sofreram modificações consideráveis com as ISE, inclusive com mudança de sinal, de acordo com o que já havia observado Holanda (1998). No caso dos momentos obtidos do modelo com EIC considerando deslocamentos prescritos $(M W O / M F 0)$, a variabilidade é devida à imposição dos recalques medidos e da rigidez da estrutura. No caso dos momentos obtidos no modelo somente com EIC (MVO/MF0), está presente apenas a influência da estrutura o que torna esse modelo aquele com a menor variação de momentos. Verifica-se também que dependendo do modelo, um mesmo pilar pode apresentar momentos com sinais trocados ou não, além de intensidades notadamente diferentes. Os pilares P4 e P13 e P5 são os que possuem menor rigidez em relação a seus respectivos pórticos. Os 
pilares P4 e P13 não possuem travamento algum no $1^{\circ}$ pavimento. Apesar de Pilar P8 estar na mesma condição dos pilares P4 e P13, sua proximidade com Pilar P9 tende a distribuir os esforços. No caso do pórtico P5 e P6, nota-se que o Pilar P6 forma pórtico diretamente ao Pilar P7, pilar mais rígido do edifício, tornando-o mais rígido que o Pilar P5. Nos casos observados, há uma tendência de migração de momentos dos elementos mais rígidos para os menos rígidos. Verifica-se que as diferenças são maiores nas proximidades dos pavimentos inferiores, onde o efeito da ISE é mais pronunciado, conforme verificado por Iwamoto (2000). O modelo $M W O / M F O$ apresenta esse mesmo comportamento.

\section{Conclusão}

A análise de uma edificação com modelos que utilizam a previsão de recalques em grupos de estacas (utilizando métodos consagrados na literatura e pela norma brasileira) para realização de ISE, com modelo que considera somente o efeito do EIC, assim como com modelo que considera o EIC em conjunto com deslocamentos prescritos, conduziram às conclusões relatadas a seguir.

Para um mesmo edifício e um mesmo perfil de solo, as previsões de recalques podem variar de forma significativa, influenciando os coeficientes de mola e consequentemente as ISE.

O modelo que considera os apoios como indeslocáveis $(F O)$, o que representa uma situação irreal, pode conduzir a valores e comportamentos de esforços axiais e de momentos fletores nos pilares bem diferentes de modelos que consideram a ISE e deslocamentos prescritos.

As diferenças de esforços (esforços axiais e momentos fletores) observadas nos diferentes modelos, indicam que as incertezas na previsão de recalques devem ser levadas em conta no dimensionamento dos elementos estruturais.

As ISE nem sempre apresentam o comportamento comumente esperado de ações axiais, ou seja, migrando de pilares centrais para pilares periféricos, visto que esse mecanismo é dependente das inter-relações entre o solo, elementos de fundação e estrutura.

O modelo de considera somente o EIC se mostrou bastante diferente do modelo que considera o EIC associado a deslocamentos prescritos, o que evidencia que modelos que incorporam somente o EIC são insuficientes na previsão do comportamento estrutural, e consequentemente, na distribuição de esforços.

Nenhum modelo que utilizou ISE teve comportamento ou valores de esforços axiais e momentos fletores compatíveis com o modelo que considerou o EIC associado aos deslocamentos prescritos, modelo este que mais se aproxima do comportamento real da estrutura, uma vez que leva em conta o histórico das ações e os deslocamentos medidos dos apoios.

Portanto, fica claro que a utilização do modelo clássico, aquele que considera os apoios de pilares como sendo fixos, assim como a consideração de modelos que contemplam ISE, podem conduzir a esforços de magnitudes bem diferentes, conduzindo a incertezas que se refletem na segurança das estruturas e fundações.

Sugere-se, para trabalhos futuros, avaliar o impacto das incertezas causadas pela previsão de recalques no índice de confiabilidade e na probabilidade de ruína de fundações profundas.

\section{Referências}

Associação Brasileira de Normas Técnicas. (2019). Projeto e execução de fundações (Norma NBR 6122).

Antunes, W.R., \& Cabral, D.A. (1996). Capacidade de carga de estacas hélice contínua. $3^{\circ}$ Seminário de Engenharia de Fundações Especiais e Geotecnia, 2 , 105-109.

Aoki, N., \& Lopes, F. R. (1975). Estimating stresses and settlements due to deep foundations by theory of elasticity, Proceedings, 5th Pan American CSMFE, $1,377-386$.

Aoki, N. (1997). Aspectos geotécnicos da interação solo-estrutura de solos. XXVIII Jornadas Sul Americanas de Engenharia Estrutural, 1, 7-20. 
Asadi-Ghoozhdi, H. \& Attarnejad, R. (2020). The effect of nonlinear soil-structure interaction on the ductility and strength demands of vertically irregular structures. Int J Civ Eng. https://doi.org/10.1007/s40999-020-00529-0

Bahia, G. A. D. (2015). Avaliação do desempenho de fundaçães em edificação no DF com a utilização de técnicas de interação solo-estrutura. Dissertação (Mestrado em Geotecnia) - Universidade de Brasília, DF.

Danziger, B. R., Costa, R. V., \& Danziger, F. A. B. (2005). Estudo de caso de obra com análise da interação solo estrutura. Engenharia Civil, $23,43-54$.

Das, B.M., \& Sobhan, K. (2014). Principles of geotechnical engineering (8th ed.) Cengage Learning.

Dhadse, G.D., Ramtekkar, G. D. T., \& Govardhan, B. (2020). Finite element modeling of soil structure interaction system with interface: a review. Archives of Computational Methods in Engineering. https://doi.org/10.1007/s11831-020-09505-2

Farias, R.S. (2018). Análise estrutural de edifícios de paredes de concreto com a incorporação da interação solo-estrutura e das ações evolutivas. Tese (Doutorado em Estruturas) - Escola de Engenharia de São Carlos. São Paulo, SP.

Gowthaman, S., Nasvi, M.C.M., \& Krishnya, S. (2017). Numerical study and comparison of the settlement behaviours of axially loaded piles using different material models. Engineer: Journal of the Institution of Engineers, 50 (2), 01-10. http://doi.org/10.4038/engineer.v50i2.7247

Gusmao, A. D. (1990). Estudo da interação solo-estrutura e sua influência em recalques de edificações. Mestrado (Engenharia Civil) - Universidade Federal do Rio de Janeiro, RJ.

Gusmão, A. D. (1994). Aspectos Relevantes da Interação Solo - Estrutura em Edificações. Soils and Rocks, 17(1), 47-55.

Gusmão, A.D., Silva, A. C., \& Sales, M. M. (2020). Foundation-structure interaction on high-rise buildings. Soils and Rocks, 43(3), 441-459. https://doi.org/10.28927/SR.433441

Gusmão Filho, J. A. (1998). Fundações do conhecimento geológico à prática da engenharia. Editora Universitária.

Hamderi, M. (2018). Comprehensive group pile settlement formula based on 3D finite element analyses. Soils and Foundations, 58, 1-15. https://doi.org/10.1016/j.sandf.2017.11.012

Holanda JR, O. G. (1998). Interação solo-estrutura para edifícios de concreto armado sobre fundaçães diretas. Dissertação (Mestrado em Estruturas) Universidade de São Paulo, SP.

Homaei, F., Shakib, H., \& Soltani, M. (2017). Probabilistic seismic performance evaluation of vertically irregular steel building considering soil-structure interaction. Int J Civ Eng. doi: 10.1007/s40999-017-0165-z

Iwamoto, R. K. (2000). Alguns aspectos dos efeitos da interação solo-estrutura em edifícios de múltiplos andares com fundação profunda. Dissertação (Mestrado em Estruturas) - Universidade Federal de São Carlos, SP.

Kripka, M. (1990). Análise incremental construtiva de edificações. Dissertação (Mestrado em Engenharia Civil) - Universidade Federal do Rio de Janeiro, RJ.

Leite, A. C. F. (2015). Comportamento estrutural de edificações de concreto de múltiplos pavimentos considerando o efeito construtivo. Dissertação (Mestrado em Engenharia Civil) - Universidade Católica de Pernambuco, PE.

Lopes, F. R., \& Gusmão, A. D. (1991). On the influence of soil-structure interaction in the distribution of foundation loads and settlements. Proceedings, 10th ECSMFE, 1, 475-478.

Menon, N. V., \& Nogueira, R. S. (2015). Análise incremental em pórticos de edifícios altos em concreto armado. Ciência \& Engenharia (Science \& Engineering Journal), 24(1), 79-88.

Meyerhof, G.G. (1959). Compaction of sands and bearing capacity of piles. ASCE, 85, 1-29.

Mindlin, R.D. (1936). Force at a point in the interior of a semi-finite solid. Physics, 7, 295-202.

Panigrahi, S., Patil, V., Madan, S. H., \& Takkalaki, S. (2019). Importance of construction sequence analysis in design of high rise building. International Journal of Innovative Science, Engineering \& Technology, 6(4), 2348-7968.

Poulos, H.G., \& Davis, E.H. (1980). Pile foundation analysis and design. Series in Geotechnical Engineering. Wiley and Sons.

Prado, J. F. M. A. (1999). Estruturas de edifícios em concreto armado submetidas a ações de construção. Doutorado (Engenharia de Estruturas) - Escola de Engenharia de São Carlos, SP.

Qaftan, O.S., Toma-Sabbagh, T., Weekes, L., \& Augusthus-Nelson, L. (2020). Validation of a finite element modelling approach on soil-foundation-structure interaction of a multi-storey wall-frame structure under dynamic loadings. Soil Dynamics and Earthquake Engineering, 131, 1-19. https://doi.org/10.1016/j.soildyn.2020.106041

Sales, M. M., Prezzi, M., Salgado, R., Choi, Y. S., \& Lee, J. (2017). Load-settlement behavior of model pile groups in sand under vertical load. Journal of Civil Engineering and Management, 23 (8), 1148-1163. https://doi.org/10.3846/13923730.2017.1396559

Savaris, G., Hallak, P. H., \& Maia, P. C. A. (2011). Understanding the mechanism of static soil-structure interaction - a case study. Soils and Rocks, 34(3), 195-206.

Schmertmann, J. H. (1978). Estimating settlements. Guidelines for cone penetration test - performance and design. Federal Highway Administration, FHWATS-78-208, 49-56. 
Research, Society and Development, v. 10, n. 9, e42810918199, 2021

(CC BY 4.0) | ISSN 2525-3409 | DOI: http://dx.doi.org/10.33448/rsd-v10i9.18199

Silva, A. C. (2018). Interação solo-estrutura no projeto de edifícios altos. Dissertação (Mestrado em Geotecnia) - Universidade Federal de Goiás. Goiás, SP. Skempton, A.W. (1953). Piles and pile foundation, discussion, Proceedings, 3rd. ICSMFE, 3, 172-173.

Souza, J.M.S., Danziger, B.R., \& Danziger, F.A.B. (2012). The influence of the relative density of sands in SPT and CPT correlations. Soils and Rocks, 35, 99113.

Teixeira, A. H., \& Godoy, N. S. (1996). Análise, projeto e execução de fundações rasas. In W. Hachich (Ed.), Fundações: teoria e prática. (2th ed.), $227-264$. Pini.

Velloso, D. A., \& Lopes, F.R. (2002). Fundações. COPPE-UFRJ.

Yip, H.L., Au, F.T.K., \& Smith, S.T. (2011). Serviceability performance of prestressed concrete buildings taking into account long-term behaviour and construction sequence. Procedia engineering, 14, 1384-1391. 10.1016/j.proeng.2011.07.174 